\title{
PANCASILA SEBAgAi PEMERSATU BANgSA NEgARA INDONESIA
}

Salomo, Chontina Siahaan

Sophian Talenta Mendrofa (2153050016)

Mahasiswa Program Studi Teknik Sipil Universitas Kristen Indonesia

Universitas Kristen Indonesia

sophiantalentam@gmail.com

\begin{abstract}
$\operatorname{ABSTRACT}$
The nation has a variety of cultures that are different from others. Pancasila as a unifying medium for the nation, this means that Pancasila is a complete and intact device, which directly formulates the national ideals in this country, namely realizing social justice for all Indonesian people. The state aims to integrate all subsystems in existing national methods. Pancasila is also a way of life for the Indonesian people, in this case it can also unite the Indonesian people and provide guidelines for our society to achieve prosperity and inner and outer happiness through Bhineka Tunggal Ika.

The third mandate of Pancasila, namely the principle of Indonesian unity, shows that Pancasila is very focused on and maintains the value of national unity for the differences that the Indonesian people have, be it the plurality of languages (regions), ethnic groups, interest groups, culture, politics, and more. and with religion. This means that the leaders of the nation, especially the initiators of the nation and state who are involved in the preparation of the founding countries, understand and at the same time appreciate the differences that exist in Indonesian society and this country requires a unifying instrument for the nation. The introduction of the principle of the third precept is in addition to instilling a sense of the meaning of unity and integrity for the sustainability of the life of the Indonesian nation and state.
\end{abstract}

Keywords: Diversity, Pancasila, Unifying the Nation

\begin{abstract}
ABSTRAK
bangsa memiliki beragam budaya yang berbeda dengan yang lain. Pancasila menjadi media pemersatu bangsa hal ini mengartikan Pancasila merupakan suatu perangkat yang utuh dan utuh, yang secara langsung merumuskan cita-cita nasional di negara ini, yaitu merealisasikan keadilan sosial bagi seluruh rakyat Indon esia. Negara bertujuan memadukan semua subsistem dalam metode nasional yang ada. Pancasila juga merupakan way of life bangsa Indonesia, dalam hal ini juga dapat mempersatukan bangsa Indonesia dan memberikan pedoman bagi masyarakat kita untuk menggapai kesejahteraan serta kebahagiaan lahir batin melalui Bhineka Tunggal Ika.

Amanat ketiga Pancasila, yaitu sila persatuan Indonesia, menunjukkan jika Pancasila sangat memusatkan dan mempertahankan nilai penggabungan bangsa atas perbedaan yang dimiliki bangsa Indonesia, baik itu kemajemukan bahasa (daerah), suku, kelompok
\end{abstract}


kepentingan, budaya, politik, dan lebih. dan dengan agama. Artinya, para pemimpin bangsa, khususnya para penggagas bangsa dan negara yang terlibat pada persiapan negara pendiri, memahami dan sekaligus menghargai perbedaan yang terdapat di masyarakat Indonesia dan negara ini membutuhkan perangkat pemersatu bangsa. Pengenalan prinsip sila ketiga ini selain untuk menanamkan rasa berartinya persatuan dan kesatuan bagi kesinambungan hidup bangsa dan negara Indonesia.

Kata Kunci : Keberagaman, Pancasila, Pemersatu Bangsa 


\section{PENDAHULUAN}

Negara Indonesia dikenal dengan negara kepulauan dengan keanekaragamannya, 70\% dari keseluruhan wilayah Indonesia adalah air sehingga menjadikan wilayah Indonesia terpecah menjadi pulau-pulau. Indonesia memiliki kebudayaan atau adat istiadat dan bahasa yang beranekaragam dengan 300 suku yang tersebar di 17.504 total pulau yang ada di Indonesia dan tersebar dari ujung utara (Sabang) hingga ujung timur (Merauke) Indonesia.

Keberagaman yang dimiliki Indonesia mendorong para leluhur untuk melahirkan satu dasar negara yang mampu mengikat keberagaman tersebut. Pancasila merupakan dasar negara yang dibentuk melalui rapat BPUPKI yang diselenggarakan pada 29 Mei 1945. Pancasila tidak dibentuk instan, akan tetapi telah melewati proses yang cukup panjang, para penggagas negara (the founding fathers) menggali nilai mutu yang ada dalam Pancasila yang serupa budaya bangsa Indonesia.

Pancasila memiliki fungsi dan susunan bagi negara Indonesia, yakni Pancasila menjadi Perjanjian Luhur, Pancasila sebagai Dasar Negara, Pancasila menjadi Ideologi Bangsa, Pancasila menjadi Filsafat Bangsa, Pancasila menjadi Pandangan Hidup, Pancasila menjadi Jiwa dan Kepribadian Bangsa, Pancasila menjadi Pemersatu Bangsa, Pancasila menjadi Etika Politik, Pancasila menjadi Paradigma Kehidupan dalam Masyarakat Berbangsa serta Bernegara.

Menjadi dasar negara, Pancasila tercantum sesuai dengan konstitusi negara dalam UUD 1945 gugus kalimat keempat yang disimpulkan dalam menciptakan suatu pemerintahan negara Indonesia dan menumbuhkan ketentraman umum, mencerdikkan kelangsungan hidup bangsa dan turut menjalankan keamanan dunia yang berlandaskan kemerdekaan, keamanan dan kenyamanan dan kesetaraan sosial, kemudian 
mengembangkan kemerdekaan kebangsaan Indonesia, yang dibentuk dalam struktur negara Republik Indonesia yang berdaulat dari rakyat didasarkan oleh kelima Pancasila.

Dasar negara yaitu Pancasila mengartikan bahwa Pancasila dijadikan sebagai asas dalam menjalankan tatanan pemerintahan Negara Indonesia. Hal tersebut menjadi sumber segala hukum yang menata kehidupan berbangsa, bermasyarakat, dan bernegara. Ketentuan ini tertuang pada Ketetapan MPRS No. XX/MPRS/1966 tanggal 16 Juli 1966 yang mengesahkan Memorendum DPRGR tanggal 9 Juli 1966 mengenai sumber ketertiban hukum Negara Kesatuan Republik Indonesia serta Tatanan Perundang-undangan Negara Kesatuan Republik Indonesia, telah dijelaskan bahwa asal hukum Negara Kesatuan Republik Indonesia merupakan hukum dan norma hukum, kesadaran serta cita-cita. Moralitas yang meliputi seluruh jiwa dan karakter bangsa Indonesia, yaitu kemerdekaan individu, jati diri bangsa, moralitas dan moralitas, perdamaian nasional dan dunia, kemanusiaan, cita-cita politik, keadilan sosial, cita-cita geraham mulia yang meliputi perwujudan hati nurani manusia, terkait dengan hakikat bentuk dan tujuan negara. Pada tanggal 18 Agustus cita-cita moral yang luhur serta cita-cita hokum, nilai kehidupan, dan kesadaran, termasuk kondisi kejiwaan dan sifat bangsa Indonesia, disucikan dan dikonsentrasikan pada landasan oleh badan persiapan kemerdekaan yang di atas namakan rakyat Indonesia. (Taniredja, dkk, 2014:38).

Pancasila sebagai pemersatu bangsa maksudnya adalah bahwa Pancasila mengandung tujuan bangsa dan Negara untuk merealisasikan sila kelima sehingga Pancasila menjadi alat pemersatu. Cita-cita negara ini mampu menyatukan bagian secara keseluruhan dalam sistem nasional yang ada. Pancasila juga menjadi ideologi bangsa Indonesia, dimana hal ini juga dapat mengintegrasikan bangsa Indonesia serta menyampaikan informasi menggapai kesejahteraan dan kebahagiaan lahir batin pada kehidupan masyarakat yang berBhineka Tunggal Ika. (Bakry dalam Taniredja, 2014:98)

\section{METODE}

Metode yang digunakan ialah metode studi pustaka, karena data yang diperoleh dikumpulkan dengan cara menggali informasi dari buku dan jurnal. Kemudian data yang diperoleh diuraikan secara deskriptif. 


\section{HASIL DAN PEMBAHASAN}

Weltanschauung merupakan Pancasila yang berarti satu dasar falsafah. Pada hakikatnya Pancasila dijadikan sebagai alat yang menyatukan bangsa Indonesia dalam bertempur selama bertahun-tahun melawan imprialisme untuk menggapai kemerdekaan. Perlu digaris bawahi bahwa dua bangsa tidak memungkinkan berjuang dengan usaha yang sama. Oleh sebab itu, bangsa secara individu memiliki kepribadiannya sendiri yang tercipta dalam berbagai hal baik secara perekonomiannya, wataknya, kenyataannya, dan sebagainya (Pimpinan MPR dan Tim Kerja Sosialisasi MPR dalam Ristekdikti, 2016: 96).

Indonesia merupakan Negara yang dikenal dengan keberagamannya baik itu agama, ras, suku, serta adat istiadat. Hal ini lah yang menganggap Pancasila bisa menjadi persatuan dan kesatuan melalui mutu yang tercantum dalam Pancasila. Menurut Effendi dalam Taniredja (2014) bahwa dalam praktik sejarah pelaksanaan ketatanegaraan di Indonesia telah membuktikan bahwa Pancasila mampu mengatasi perbedaan-perbedaan pendapat pertentangan antar golongan rakyat/daerah. Perbedaan atau pertentangan sebesar apapun yang timbul akan kembali reda dan dapat diatasi ketika perbedaan itu dikembalikan kepada falsafah Pancasila.

Para leluhur dan pendahulu bangsa, khususnya the founding fathers yang memiliki peranan dalam proses penyusunan dasar negara, memahami dan sekaligus menyadari keberagaman yang ada dalam masyarakat Indonesia dan Negara ini memerlukan penyatuan bangsa. Sila ketiga selain menanamkan rasa berartinya persatuan dan kesatuan untuk kesinambungan hidup bangsa dan Negara Indonesia. Sila ketiga Pancasila menunjukkan jika Pancasila sangat menegaskan dan menghormati tinggi nilai persatuan bangsa diatas perbedaan-perbedaan yang dimiliki oleh bangsa Indonesia baik itu perbedaan golongan kepentingan, bahasa (daerah), politik, budaya, suku bangsa bahkan juga agama.

Bhineka Tunggal Ika adalah semboyan negara yang sangat dibangun dalam Pancasila, yang terkandung dalam simbol Garuda Pancasila Bhineka Tunggal Ika bersumber dari bahasa Jawa kuno yang diperkenalkan oleh Mpu Tantular dalam Kitab Sutasoma, artinya walaupun berbeda tetapi tetap satu. Semboyan ini memiliki tujuan yang sama dengan Pancasila, yaitu untuk mempersatukan bangsa Indonesia, menjaga persatuan 
bangsa, meminimalkan konflik kepentingan pribadi atau kelompok dan mencapai cita-cita negara Indonesia. (Dewantara, Nurgiansah, dalam Pertiwi, 2021)

Bhinneka Tunggal Ika menjadi motto bangsa Indonesia juga tertera pada Peraturan Pemerintah No. 66 Tahun 1951 dan Undang-Undang Republik Indonesia Nomor 24 Tahun 2009 mengenai Bendera, Bahasa, dan Lambang Negara serta Lagu Kebangsaan yang menerangkan di bawah lambang yang tercatat dengan huruf latin dalam bahasa Jawa, sebuah slogan yang bermakna: Bhinneka Tunggal Ika, kata Bhinneka merupakan perpaduan dari dua kata: Bhinna dan ika. Secara menyeluruh didefinisikan sebagai, 'berbeda tapi tetap satu'

Pancasila dibentuk melewati proses yang panjang dan cukup pelik. Perumusan Pancasila diawali dari Indonesia yang dijajah oleh bangsa Jepang. Pada tahun 1944, Jepang berusaha meminta pertolongan dari bangsa dengan memberikan iming-iming akan menyerahkan kemerdekaan kepada bangsa Indonesia. Hal ini disebabkan situasi Jepang yang berada diambang kekalahan akan pihak sekutu. Akan tetapi, Jepang belum juga menunjukkan tanda-tanda itikad baiknya sehingga bangsa Indonesia menuntut Jepang atas kemerdekaan Indonesia yang pernah dijanjikan oleh Jepang kepada Indonesia. Untuk sebagai pembuktian tanggung jawab Jepang mengenai komitmen tersebut maka pada 1 Maret 1945 Jepang memaklumkan rencana pendirian suatu badan yangakan mempersiapakan kemerdekaan, yang diketahui dengan nama Badan Penyelidik UsahaUsaha Persiapan Kemerdekaan Indonesia (BPUPKI). Akan tetapi lembaga ini tercipta pada 29 April 1945 serta kepengurusan diangkat pada 28 Mei 1945 lalu pada 29 Mei 1945 BPUPKI menyelenggarakan sidang pertama sebagai tanda bahwa badan ini telah aktif dan mulai bekerja. BPUPKI memiliki anggota sebanyak 60 orang yang diketuai oleh ketua Dr. Radjiman Widiodiningrat.

Terbentuknya BPUPKI, memberikan legalitas kepada bangsa Indonesia dalam merencanakan sebuah Negara yang merdeka, meringkaskan permintaan yang harus dijalankan bagi sebuah Negara merdeka termasuk perumusan dasar Negara. Hal ini menjadi hal perdana dibicarakan dalam sidang pertama BPUPKI. Sidang BPUPKI diselenggarakan sebanyak dua kali, sidang pertama diselenggarakan tanggal 29 Mei hingga 1 Juni 1945, 
terciptanya sidang pertama diulas kembali di sidang kedua yang dijalankan pada 14 hingga 16 Juli 1945. (Brata, 2017)

Sidang pertama BPUPKI menghasilkan 3 usulan calon dasar Negara, yaitu

1. Mr. Muh. Yamin mengutarakan usulan Dasar Negara Indonesia yaitu:

- Kewarganegaraan

- Peri Kemanusiaan

- Peri Ketuhanan;

- Peri Kerakyatan (perembukan dan perutusan)

- Ketentraman Rakyat (Keadilan sosial)

2. Mr. Soepomo mengutarakan usulan calon Dasar Negara yaitu;

- patriotisme/internasionalisme;

- berserah diri kepada tuhan

- Kerakyataan

- kehangatan

- Kesamarata dan keseimbangan rakyat.

3. Ir. Soekarno memberikan Dasar Negara yang diberi nama Pancasila kesimpulannya adalah;

- Patriotisme (kebangsaan Indonesia)

- Internasionalisme (peri kemanusiaan)

- sepaham (demokrasi)

- Ketentraman masyarakat; dan

- Ketuhanan Yang Maha Esa (Ketuhanan yang berperadaban).

BPUPKI menyelenggarakan sidang yang kedua dengan rancangan memusyawarahkan pidato terkait dengan ajuan aspirasi asas dasar negara yang sudah diinformasikan untuk tiga tokoh dalam sidang pertama. Pembicaraan terhadap ketiga ajuan aspirasi pilar dasar negara tidak dibicarakan kembali oleh seluruh anggota BPUPKI, 
akan tetapi dibahas oleh Panitia Sembilan, yaitu Ir. Soekarno, Mr. A.A. Maramis, Drs. Moh. Hatta, Mr. Ahmad Soebardjo, K.H. Wachid Hasym, Abikoesno Tjokro Soejoso, Mr. Muh. Yamin, Abdoel Kahar Muzakir, dan Haji Agus Salim. Panitia Sembilan menyelenggarakan rapat mendalam mulai tanggal 14 hingga 16 Juli 1945, sampai Panitia Sembilan sudah menggapai suatu pencapaian penciptaan Pancasila, yang biasa dikenal dengan sebutan Piagam Jakarta, berikut merupakan susunannya:

1. Ketuhanan yang diharuskan bagi masyarakat Indonesia dengan selalu melaksanakan syariat Islam bagi yang beragama Islam

2. Kemanusiaan yang adil dan beradab.

3. Persatuan Indonesia

4. Kerakyatan yang dipimpin oleh hikmat kebijaksanaan dalam permusyawatan perwakilan

5. Keadilan sosial bagi seluruh rakyat Indonesia.

Panitia Persiapan Kemerdekaan Indonesia (PPKI) yang diciptakan pada 7 Agustus 1945 dan mulai beroperasi pada 9 Agustus 1945 melanjutkan hasil rapat panitia yang beranggotakan sembilan orang. Tokoh-tokoh bangsa yang beragama non-muslim, terutama yang berasal dari Indonesia timur, menentang keputusan dalam perintah pertama, dan mereka mengancam bahwa jika keputusan itu tidak diubah, mereka akan mendirikan negara mereka sendiri. Kemudian sebelum rapat PPKI pertama dimulai, Bung Hatta, Kasman Singodimejo, Ki Bagus Hadikusumo, Teuku Moh. Hassan, dan K.H. Abdul Wachid Hasyim membicarakan persoalan tersebut sehingga untuk melindungi persatuan dan kesatuan bangsa Indonesia, kalimat ini dihapus serta diubah sebagai "Ketuhanan Yang Maha Esa".

PPKI mempunyai tugas untuk mengawasi hasil-hasil BPUPKI, lalu memiliki fungsi serta strata yang sungguh berharga yaitu:

1. Sebagai pemangku seluruh masyarakat Indonesia

2. Menjadi pencetus Negara (yang membentuk Negara Republik Indonesia sesudah Proklamasi Kemerdekaan 17-18 Agustus 1945).

3. Menempatkan dasar negara (prinsip pedoman negara yang fundamental) 
Jepang mengakui keruntuhannya dan mengangkat tangan kepada sekutu pada 15 Agustus 1945. Kendati diawalnya keruntuhan Jepang sangat ditutupi, tetapi dikarenakan kecerdikan dan kecakapan para teruna khususnya para teruna yang berdinas di Kantor Berita, kabar keruntuhan Jepang terdengar oleh para pemimpin gerakan Indonesia. Selagi sekutu menyampaikan instruksi kepada Inggris untuk melucuti senjata Jepang. Amanat Sekutu kepada Inggris tidak serta merta dilaksanakan, sehingga menimbulkan kekosongan kekuasaan di Indonesia. Keruntuhan Jepang oleh sekutu dan kosongnya kekuasaan ini menjadi alasan mengapa aktivis pemuda pennindakan nasional Indonesia menuntut Ir. Soekarno dan Drs. Moh. Hatta untuk segera memproklamasikan kemerdekaan Indonesia. Akhirnya pada pukul 10.00 WIB yang berada di Jl. Pegangsaan Timur No. 56 Jakarta "Proklamasi Kemerdekaan Indonesia" diberitakan oleh dwitunggal (Soekarno-Hatta) pada tanggal 17 Agustus 1945 atas nama rakyat Indonesia.

Tanggal 18 Agustus 1945 PPKI mewujudkan rapat final dan akhirnya memvaildasikan Undang-Undang Dasar, yang diketahui dengan UUD 1945 dan Pancasila sebagai Dasar Negara, yang isinya terkandung pada gugus kalimat keempat Pembukaan UUD 1945 tanggal 18 Agustus dengan isi Pancasila yakni sebagai berikut:

1. Ketuhanan Yang Maha Esa.

2. Kemanusiaan yang adil dan beradab.

3. Persatuan Indonesia.

4. Kerakyatan yang dipimpin oleh hikmat kebijaksanaan dalam permusyawaratan / perwakilan.

5. Keadilan sosial bagi seluruh rakyat Indonesia.

Hasil rapat tersebut juga menghasilkan ketetapan Ir. Soekarno sebagai Presiden dan Drs. Moh. Hatta menjadi Wakil Presiden Republik Indonesia, dengan demikian selaku de facto dan selaku de yure Indonesia menjadi negara merdeka setelah menetapkan Pancasila menjadi Dasar Negara dan juga menjadi penggabungan bangsa Indonesia. Pancasila disetujui menjadi jati diri bangsa, dasar negara, pandangan hidup yang bersifat terbuka, dan falsafah bangsa,. 
Pancasila sebagai pemersatu bangsa menerima prinsip aliran Negara satu kesatuan dalam arti:

1. Melindungi seluruh rakyat dan melingkupi sepenuh suku bangsa negara

2. Mengatasi persoalan segala paham baik golongan maupun perorangan yang dilakukan oleh negara

3. Melindungi seluruh tumpah darah sehingga menjadi nama Negara Kesatuan Republik Indonesia.

Implementasi mutu Pancasila pada penggabungan bangsa, yaitu sebagai berikut:

1. Menanamkan karakter patriotisme cinta tanah air dalam berbangsa dan bernegara.

2. Menanamkan aksi silih menyegani antar suku, ras, dan antar golongan, agama dan tidak mematakan divergensi.

3. Menumbuhkan penggabungan dan keesaan agar terciptanya kesuksesan bangsa negara.

4. Memaknai sejarah Indonesia agar menjadi penyemangat penggabungan

\section{KESIMPULAN}

Negara Indonesia merupakan negara kepulauan yang terkenal dengan keanekaragamannya, 70\% dari keseluruhann wilayah Indonesia adalah air sehingga menjadikan wilayah Indonesia terpecah menjadi pulau-pulau. Indonesia memiliki 17.504 pulau yang mana pulau-pulau tersebut tersebar mulai dari Sabang sampai Merauke hal ini menghasilkan kebudayaan atau adat istiadat dan bahasa yang beranekaragam. Indonesia mempunyai beraneka suku bangsa yaitu sebanyak lebih dari 300 suku bangsa, dimana pada tiap suku bangsa mempunyai ragam budaya yang berbeda antara satu dengan yang lain. Setiap suku bangsa memiliki tatanan sosial yang mengikat masyarakatnya agar taat dan melaksankan aturan-aturannya.

Dalam keberagaman yang dimiliki tersebut, bangsa Indonesia memiliki Pancasila sebagai alat pemersatu bangsa yang dilahirkan melalui prosedur yang panjang. Pancasila sebagai Dasar Negara, yang rancangannya terdapat dalam gugus kalimat keempat 
Pembukaan UUD 1945 yaitu Ketuhanan Yang Maha Esa, Kemanusiaan yang adil dan beradab, Persatuan Indonesia, Kerakyatan yang dipimpin oleh hikmat kebijaksanaan dalam permusyawaratan/perwakilan, Keadilan sosial bagi seluruh rakyat Indonesia.

Pancasila diciptakan melalui prosedur yang panjang dan cukup pelik. Perumusan Pancasila diawali dari Indonesia yang dijajah oleh bangsa Jepang. Pada tahun 1944, Jepang berusaha meminta pertolongan dari bangsa dengan memberikan iming-iming akan menyerahkan kemerdekaan kepada bangsa Indonesia. Hal ini disebabkan situasi Jepang yang berada diambang kekalahan akan pihak sekutu. Akan tetapi, Jepang belum juga menunjukkan tanda-tanda itikad baiknya sehingga bangsa Indonesia menuntut Jepang atas kemerdekaan Indonesia yang pernah dijanjikan oleh Jepang kepada Indonesia.Sehingga sebagai pembuktian Jepang kepada Indonesia diciptakannya BPUPKI dan PPKI. Terbentuknya BPUPKI, memberikan legalitas kepada bangsa Indonesia untuk merencanakan menjadi sebuah Negara yang otonom, meremukkan persyaratan yang harus dijalankan bagi sebuah Negara merdeka termasuk perumusan dasar Negara. PPKI mempunyai tugas untuk mengawasi hasil-hasil BPUPKI, lalu memiliki fungsi dan strata yang begitu berarti yaitu sebagai pemangku seluruh masayarkat Indonesia menjadi pencetus Negara (yang membentuk Negara Republik Indonesia setelah Proklamasi Kemerdekaan 17-18 Agustus 1945), menempatkan dasar negara (prinsip pedoman negara yang fundamental). 


\section{DAFTAR PUSTAKA}

Brata, I. B. (2017). Lahirnya Pancasila Sebagai Pemersatu Bangsa Indonesia. Jurnal Santiaji Pendidikan.

Dewi, A. D. (2021). Implementasi Nilai Pancasila Sebagai Landasan Bhinneka Tunggal Ika. Jurnal Kewarganegaraan.

Kemahasiswaan, D. J. (2016). Pendidikan Pancasila Untuk Perguruan Tinggi. Jakarta: Ristekdikti.

Taniredja, d. (2014). Kedudukan dan Fungsi Pancasila Bagi Bangsa dan Negara Indonesia. Bandung: Alfabeta. 